\title{
Peertechz
}

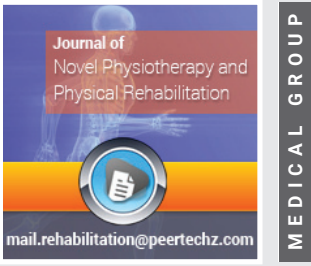

\section{Leisure time physical activity, sedentary behavior and risk of cardiovascular disease and mortality among US Veterans}

\author{
Luc Djousse ${ }^{1-3 *}$, Petra Schubert ${ }^{1}$, Yuk-Lam Ho ${ }^{1}$, Stacey B \\ Whitbourne $^{1-3}$, Kelly Cho ${ }^{1-3}$ and J Michael Gaziano ${ }^{1-3}$ \\ ${ }^{1}$ Massachussets Veterans Epidemiology Research and Information Center, VA Boston Healthcare \\ System, Boston, MA, United States \\ ${ }^{2}$ Harvard Medical School, Boston, MA, United States \\ ${ }^{3}$ Department of Medicine, Division of Aging, Brigham and Women's Hospital in Boston, Massachusetts, \\ United States
}

Received: 21 September, 2021

Accepted: 30 September, 2021

Published: 01 October, 2021

*Corresponding author: Luc Djousse, Massachusetts Veterans Epidemiology Research and Information Center, VA Boston Healthcare System, 150 S Huntington Ave, Boston, MA 02130, United States, Tel: 857-3646930; E-mail: Ldjousse@rics.bwh.harvard.edu

ORCID: https://orcid.org/0000-0002-9902-3047

Keywords: Physical activity; Epidemiology; Cardiovas cular disease; Risk factors

Copyright: @ 2021 Djousse L, et al. This is an openaccess article distributed under the terms of the Creative Commons Attribution License, which permits unrestricted use, distribution, and reproduction in any medium, provided the original author and source are credited.

https://www.peertechzpublications.com

\section{Check for updates}

\section{Abstract}

Background: Cardiovascular Disease (CVD) remains the leading cause of death in the US. Although Physical Activity (PA) has been inversely associated with the risk of CVD, few studies have examined whether sedentary behaviors modify such association. Our goal was to examine associations of leisure time PA with risk of CVD and mortality and the role of sedentary behavior as potential effect modifier among US veterans.

Methods: We analyzed self-reported data on leisure time PA, television watching, and time spent on the computer among 438,364 participants of the Veterans Affairs Million Veteran Program from 2011 to 2018. We calculated metabolic equivalent of task-hours per week (MET-h/week) for each person and used electronic health record data to ascertain CVD.

Results: Mean age was $64.6 \pm 12.6$ years and $92 \%$ were men. During a mean follow up of 3.3 years, we observed 22,942 new cases of CVD and 48,325 deaths. There was an inverse relation of leisure time PA with CVD and total mortality [HR: 0.96 (0.95-0.97) and 0.91 (0.90-0.92) per 2 MET-h/week increment for CVD and total mortality, respectively]. The associations of PA with both incident CVD and mortality were stronger in participants who spent more time watching television or on computer (all $\mathrm{p}$ values for interaction $<0.01)$. No interaction of PA with time spent on video game was observed $(p>0.05)$.

Conclusions: Leisure time PA is inversely associated with risk of CVD and mortality among US veterans and such relations were stronger in participants who spent more time watching television or on computer.

\section{Introduction}

Despite a noticeable decline in deaths from cardiovascular diseases over the past decades, Atherosclerotic Cardiovascular Disease (ASCVD) remains one of the leading causes of death in the Unites States and is associated with high costs [1]. While modifiable lifestyle factors including Physical Activity (PA) have been reported to reduce the risk of ASCVD in the general population [2-6], limited data are available on the association of leisure time PA and incidence of ASCVD and mortality among
US veterans. Both the 2018 Physical Activity Guidelines for Americans [7] and the 2019 CVD Primary Prevention Clinical Practice Guidelines [8] recommend $\geq 150$ minutes per week of moderate intensity such as brisk walking (equivalent of 7.5 MET-h per week) or $\geq 75$ minutes per week of vigorousintensity activity (i.e., shoveling snow) for adults for health benefits. Unfortunately, current data suggest that only one in five American adults and less than $25 \%$ of US veterans meet these recommended goals for PA [1]. It is less clear whether PA levels below the recommended amount, which are highly 
prevalent in older adults, are associated with lower ASCVD or mortality risk among US veterans. Furthermore, sedentary behavior (i.e., hours spent watching television) is highly prevalent in the US with adults spending on average 10.5 hours per day connected on media including television and computer [1]. Sedentary behavior has been positively associated with type 2 diabetes [9], ASCVD [10], and mortality [9,11]. However, it is unclear whether people who spend more time in sedentary behaviors benefit the most from PA compared to those in the lowest categories of sedentary behaviors. Thus, the current project sought to prospectively test the (i) primary hypothesis that leisure time PA is inversely associated with incidence of ASCVD and mortality and (ii) secondary hypothesis that sedentary behavior modifies the association of leisure time PA with incident ASCVD and/or mortality among participants of the Veterans Affairs (VA) Million Veteran Program (MVP).

\section{Methods}

\section{Population}

MVP is an ongoing prospective cohort study and large biorepository designed to study genetic determinants of chronic diseases among US veterans who use Veterans Health Administration (VHA) services. All veterans signed informed consent and the VA Central Institutional Review Board approved the study protocol in 2010. Details on design and methodology of MVP have been published elsewhere [12]. As of January 19, 2019, 702,740 veterans have been enrolled. Among enrollees, 475,118 participants provided self-report data through the Baseline and/or Lifestyle Survey with questions about modifiable lifestyle factors including leisure time PA. A total of 470,251 answered survey questions on leisure time PA and after exclusion of 31,344 participants with no Electronic Health Record (EHR) follow up data and exclusion of 542 participants missing age, we used information on 438,364 participants for current analyses. Details on exclusion criteria are presented in the flow chart (supplementary Figure 1).

\section{Assessment of leisure time PA}

Item 24.c of the Lifestyle Survey asked the following question about leisure time PA: "During your leisure or free time, how often do you engage in the following levels of activity?" Three levels were specified as follows: "Vigorous (e.g., competitive sports like running, swimming, or high intensity aerobics)"; "Moderate (e.g., low impact aerobics, or golfing without a power cart)"; and "Light (e.g., bowling, archery, easy walking, golfing with a power cart, fishing)". Response options included: "Never" [o/week]; "Once/month or less" [0.25/week]; "Several times/month"[0.625/week]; "Once per week"[1/week]; "Several times/week"[4/week]; and "Daily" [7/week]. On the Baseline Survey, item \# 29 asked participants to report their level of vigorous physical activity: "How often do you exercise vigorously enough to work up a sweat?". Pre-specified answers were: "rarely/Never"[o/week]; "1-3 times a month"[0.5/week]; "Once a week" [1/week]; "2-4 times a week"[3/week]; "5-6 times a week"[5.5/week]; and "Daily" [7/week]. We use answers to these questions on leisure time PA to compute MET-h/week. For participants with missing data on leisure time PA (item $24 \mathrm{c}$ of the Lifestyle
Survey; $n=144,700$ ) we used data on vigorous physical activity obtained from the Baseline Survey (item 29) to compute MET-h/week. We made the following assumptions: a) we assigned 3, 5, and 9 METs for light, moderate, and vigorous activity, respectively [13]; b) since we did not query about the duration of each type of physical activity, we assumed fifteen minutes (15 minutes or 0.25 hour) duration for each reported frequency; and c) used the mid-point for answers that specified a range (i.e., we assigned a frequency of 5.5 times a week for "5-6 times a week") [see supplemental Table 1 for conversion of all answers]. For each of the 3 categories (light, moderate, and vigorous) of leisure time PA, we multiplied corresponding MET by duration ( 0.25 hour), and the obtained result was then multiplied by the reported frequency in weeks. Total MET-h/week was obtained by summing MET-h/week of light, moderate, and vigorous activity. In sensitivity analyses, we repeated the above algorithm using 20 and 30 minutes in duration and obtained similar correlation between MET-h/ week and HDL-cholesterol measured closest to the assessment of PA (Rho: 0.106, 0.106, and 0.106 for use of 15, 20, and 30 minutes, respectively). Since the use of 20 or 30 minutes would exaggerate level of PA among light active veterans, we chose to be conservative and err on the side of underestimation rather than overestimation of PA and retained 15 minute-duration for the current analyses. Once MET-h/wk was calculated for each participant, we grouped leisure time PA into quintiles because we did not assume a nonlinear relation between exposure and outcome.

\section{Assessment of sedentary behaviors}

Item \#30 of the Lifestyle Survey asked participants to provide information about sedentary behaviors: "During the PAST MONTH, on average, how many hours per week did you spend: Watching TV, Video, or DVD; Using a computer; Playing video games; Talking on a cell phone". Pre-specified answers were: "0, 1, 2-5, 6-10, 11-20, 21-40, 41-60, 61-90, over 90 hours". We used the mid-point for each category and the floor of the open-ended category for analyses. Since we could not assume that people are immobile while talking on the phone, we chose to focus primarily on "watching TV, video, or DVD" , time "Using a computer" and "Playing video games" as a surrogate of sedentary behaviors.

\section{Assessment of CVD and mortality}

CVD included non-fatal myocardial infarction using ICD-9 Codes 410-411, 413-414 and ICD-10 codes I20 - I25 (excluding I25.2); coronary deaths (ICD10 I20-I25); coronary angioplasty or revascularization (CPT Codes 33510-33536, 9292x, 9293x, 9294x, 92973, 92974, and 92975; ICD-9 Procedure codes 36.x and 00.66). Fatal and non-fatal stroke (both ischemic and hemorrhagic stroke): ICD-9 codes 430-431.x, 433-434.x, 436.x, 437.0x and 437.6x and ICD-10 codes I60-61.x, I63.x,I65.x, I66.X, I67.2x, I67.6x, I67.8x ; mortality was ascertained using the National Death Index (NDI) [14]. The validity of using ICD codes for the diagnosis of cardiovascular disease among veterans has been previously published [15]. Furthermore, the use of high throughput methods for phenotyping in the VA has been previously published $[16,17]$.

Citation: Djousse L, Schubert P, Ho YL, Whitbourne SB, Cho K, et al. (2021) Leisure time physical activity, sedentary behavior and risk of cardiovascular disease and mortality among US Veterans. J Nov Physiother Phys Rehabil 8(2): 033-039. DOI: https://dx.doi.org/10.17352/2455-5487.000091 
Table 1: Baseline characteristics of 438,364 participants of the Million Veteran Program by quintiles of leisure time physical activity.

\begin{tabular}{|c|c|c|c|c|c|}
\hline & \multicolumn{5}{|c|}{ Quintiles of leisure time activity (MET-h/week) } \\
\hline Characteristics & $\begin{array}{c}\text { Q1 [0] } \\
(n=91,888)\end{array}$ & $\begin{array}{l}\text { Q2 [0.1-1.24] } \\
(n=91,234)\end{array}$ & $\begin{array}{c}\text { Q3 }[1.25-3.80] \\
(n=79,405)\end{array}$ & $\begin{array}{c}\text { Q4 [3.81-6.60] } \\
(n=88,858)\end{array}$ & $\begin{array}{l}\text { Q5 [6.61-30] } \\
(\mathrm{n}=86,979)\end{array}$ \\
\hline Age $(y)^{\star}$ & $65.94 \pm 12.3$ & $65.07 \pm 12.1$ & $64.83 \pm 12.4$ & $64.31 \pm 12.9$ & $62.91 \pm 13$ \\
\hline Male Sex (\%) & $84674(92.1 \%)$ & 84003 (92.1\%) & 73051 (92 \%) & $81063(91.2 \%)$ & 79121 (91 \%) \\
\hline \multicolumn{6}{|c|}{ Race $(\%)$} \\
\hline White & $69805(76 \%)$ & $73829(80.9 \%)$ & $64853(81.7 \%)$ & $71565(80.5 \%)$ & $72311(83.1 \%)$ \\
\hline Black & 17405 (18.9 \%) & $13001(14.3 \%)$ & $10477(13.2 \%)$ & $12397(14 \%)$ & $9772(11.2 \%)$ \\
\hline \multicolumn{6}{|c|}{ Education (\%)* } \\
\hline$<$ High School & $6191(7.3 \%)$ & $3003(3.7 \%)$ & $2029(2.8 \%)$ & $2293(2.8 \%)$ & $1672(2.1 \%)$ \\
\hline$\geq$ High School & $78314(92.7 \%)$ & 78746 (96.3 \%) & $70348(97.2 \%)$ & $80084(97.2 \%)$ & $78172(97.9 \%)$ \\
\hline $\mathrm{BMI}(\mathrm{kg} / \mathrm{m} 2)^{\star}$ & $30.15 \pm 6.5$ & $30.12 \pm 5.9$ & $29.52 \pm 5.4$ & $29.06 \pm 5.3$ & $28.36 \pm 4.9$ \\
\hline \multicolumn{6}{|c|}{ Smoking Status (\%)* } \\
\hline Never & $9611(23.2 \%)$ & $15889(23.8 \%)$ & $15279(27 \%)$ & $14320(27.6 \%)$ & $22032(33.9 \%)$ \\
\hline Former & 22791 (55 \%) & 36908 (55.3 \%) & $31715(56.1 \%)$ & $29171(56.2 \%)$ & $34885(53.7 \%)$ \\
\hline Current & $9063(21.9 \%)$ & 13966 (20.9 \%) & $9515(16.8 \%)$ & $8449(16.3 \%)$ & $8008(12.3 \%)$ \\
\hline \multicolumn{6}{|c|}{ Drinker (\%)* } \\
\hline Never & 4834 (11.6 \%) & 5109 (7.7\%) & $4059(7.2 \%)$ & 3979 (7.7\%) & $4234(6.5 \%)$ \\
\hline Former & $21496(51.8 \%)$ & $28687(43 \%)$ & $21169(37.5 \%)$ & $19589(37.7 \%)$ & $20167(31.1 \%)$ \\
\hline Current & $15165(36.5 \%)$ & $32976(49.4 \%)$ & $31297(55.4 \%)$ & $28385(54.6 \%)$ & $40537(62.4 \%)$ \\
\hline Diabetes (\%) & 33115 (36 \%) & 29076 (31.9\%) & $22158(27.9 \%)$ & $22570(25.4 \%)$ & $16524(19 \%)$ \\
\hline Hypertension (\%) & $70461(76.7 \%)$ & $66125(72.5 \%)$ & $54339(68.4 \%)$ & $58585(65.9 \%)$ & $50555(58.1 \%)$ \\
\hline Dyslipidemia (\%) & $67309(73.3 \%)$ & $66169(72.5 \%)$ & $55734(70.2 \%)$ & $60543(68.1 \%)$ & $54939(63.2 \%)$ \\
\hline Atrial fibrillation (\%) & $11396(12.4 \%)$ & $9257(10.1 \%)$ & 7292 (9.2 \%) & 7644 (8.6\%) & $5992(6.9 \%)$ \\
\hline Heart failure (\%) & 11933 (13\%) & 7958 (8.7 \%) & 5295 (6.7 \%) & 5580 (6.3 \%) & 3508 (4 \%) \\
\hline DASH score* & $19.49 \pm 4.9$ & $20.06 \pm 4.8$ & $21.16 \pm 4.8$ & $21.66 \pm 4.9$ & $22.93 \pm 4.9$ \\
\hline Statin use (\%) & 60541 (65.9\%) & 57362 (62.9 \%) & 46677 (58.8 \%) & 50034 (56.3 \%) & $43111(49.6 \%)$ \\
\hline
\end{tabular}

\section{Important covariates}

We collected self-reported information on age, sex, race, education, Body Mass Index (BMI), alcohol consumption, and smoking through the Baseline Survey. Diet was assessed in MVP using the Willett semi-quantitative food frequency questionnaire, with validity and reproducibility reported previously in other cohorts [18]. We constructed a modified Dietary Approach to Stop Hypertension (DASH) (without dietary sodium since MVP did not have nutrients at the time of current analyses) to characterize overall dietary quality [3]. Prevalent CVD and other comorbidities were derived through the VHA EHR system, Corporate Data Warehouse (CDW) [19], using ICD-9 and ICD-10 codes.

\section{Statistical analysis}

We censored participants at first occurrence of CVD, death, or last recorded visit and calculated the crude incidence rate by dividing the number of outcomes by corresponding persontime. Given that baseline characteristics among the quintiles of leisure time PA were unbalanced (Table 1), we used multinomial propensity score weighting methods and employed an Average Treatment Effect (ATE) weighting strategy. Propensity score weights were estimated using Generalized Boosted Models (GBM) [20] from the weightit [21] and $\mathrm{gbm}$ [22] $\mathrm{R}$ packages and the following set of variables: age, sex, race, education, BMI, smoking, alcohol intake, and DASH score. For all-cause mortality we additionally adjusted for prevalent CVD at baseline. We considered prevalent diabetes, atrial fibrillation, heart failure, and hypertension as potential intermediate factors in the causal path of PA and CVD and therefore did not control for them. Furthermore, since PA is positively associated with HDL-cholesterol, we did not control for lipids or treatment for dyslipidemia.

Stabilized inverse probability of treatment weights (sIPTW) were calculated for each patient by converting the propensity scores. After checking for proportionality of hazards there was no violation and Cox proportional hazards models were used to estimate the crude and inverse probability weighted hazard ratios with $95 \%$ confidence intervals.

In addition to our main analyses, we evaluated the shape of the PA-outcome relation using restricted cubic splines [23] with knots placed at $25^{\text {th }}, 50^{\text {th }}$, and $75^{\text {th }}$ percentile of continuous MET-h/wk. We examined effect modification by sedentary behavior by conducting stratified analyses using 
tertiles of each of the three sedentary behaviors (time spent on television watching, computer, and video games) and utilizing the product term of leisure time PA and time spent on each sedentary behavior in an sIPTW Cox proportional hazards model to obtain $\mathrm{p}$ value for interaction. In sensitivity analysis, we excluded subjects with follow up time $<1$ year. Propensity score modeling was conducted in $\mathrm{R}$ 4.0.2, all other analyses were performed on SAS Enterprise Guide 7.1. An alpha level at 0.05 was used.

\section{Results}

Among 438,364 veterans analyzed, mean age was $64.6 \pm$ 12.6; $92 \%$ were men; $80.4 \%$ white; and $14.4 \%$ black. Median leisure time PA was 2.25 MET-h/week and 19\% met the federal guidelines recommending at least 7.5 MET-h/week. Frequent leisure time PA was associated with younger age, white race, higher educational attainment, lower body mass index and prevalence of hypertension and diabetes as expected (Table 1). We applied GBM to obtain propensity score weights in order to balance the distribution of baseline characteristics. After adjustment, the absolute standardized mean difference for every covariate was $<0.1$ indicating good balance (Supplemental Figure 2). [24] Median time spent on sedentary behavior was $15.5 \mathrm{~h} /$ week for television watching, $3.5 \mathrm{~h} /$ week for computer, and $\mathrm{o} \mathrm{h}$ /week for video games. During a mean follow up of 3.3 years (range: 0.003 to 7.7 years), 22,942 new cases of CVD and 48,325 deaths occurred. Leisure time PA was inversely associated with risk of CVD with multivariable adjusted hazard ratios ( $95 \% \mathrm{CI}$ ) of 1.00 (ref), 0.87 (0.82, 0.92$), 0.77$ (0.73, 0.82), $0.77(0.73,0.82)$ and $0.69(0.65,0.73)$ from the lowest to the highest quintile of PA, using stabilized inverse probability of treatment weights, Table 2. Similarly, we observed an inverse association of leisure time PA with risk of CAD and both ischemic but not hemorrhagic strokes (Supplemental Tables 2-4). Using restricted cubic spline, we found evidence of an inverse and linear relation between leisure time PA and risk of CVD ( $p$ non-linear <0.0001, Figure 1). Furthermore, leisure time PA was inversely associated with risk of total mortality (Table 3) as well as CVD and cancer mortality (Supplemental Tables 5,6)

The inverse associations of PA with incident CVD or

Table 2: Hazard ratios $(95 \% \mathrm{Cl})$ for CVD by leisure time physical activity in the Million Veteran Program $(\mathrm{N}=315,119)$.

\begin{tabular}{|c|c|c|c|r|}
\hline $\begin{array}{c}\text { Quintiles of leisure } \\
\text { time activity } \\
\text { (MET-h/week) }\end{array}$ & Cases/N & $\begin{array}{c}\text { Crude } \\
\text { incidence } \\
(/ 1000 P Y)\end{array}$ & Crude & SIPTW \\
\hline Q1 (0) & $5,628 / 58,434$ & 30.9 & $1.00($ ref) & $1.00($ ref $)$ \\
\hline Q2 (0.1-1.24) & $4,992 / 63,262$ & 25.1 & $0.81(0.78,0.84)$ & $0.87(0.82,0.92)$ \\
\hline Q3 (1.25-3.80) & $4,022 / 57,932$ & 21.9 & $0.71(0.68,0.74)$ & $0.77(0.73,0.82)$ \\
\hline Q4 (3.81-6.60) & $4,427 / 66,053$ & 21.1 & $0.68(0.66,0.71)$ & $0.77(0.73,0.82)$ \\
\hline Q5 (6.61-30) & $3,873 / 69,438$ & 17.5 & $0.57(0.54,0.59)$ & $0.69(0.65,0.73)$ \\
\hline p linear trend & & & $<0.0001$ & $<0.0001$ \\
\hline
\end{tabular}

†Adjusted for age, sex, race, education, body mass index, smoking, alcohol intake, and DASH score
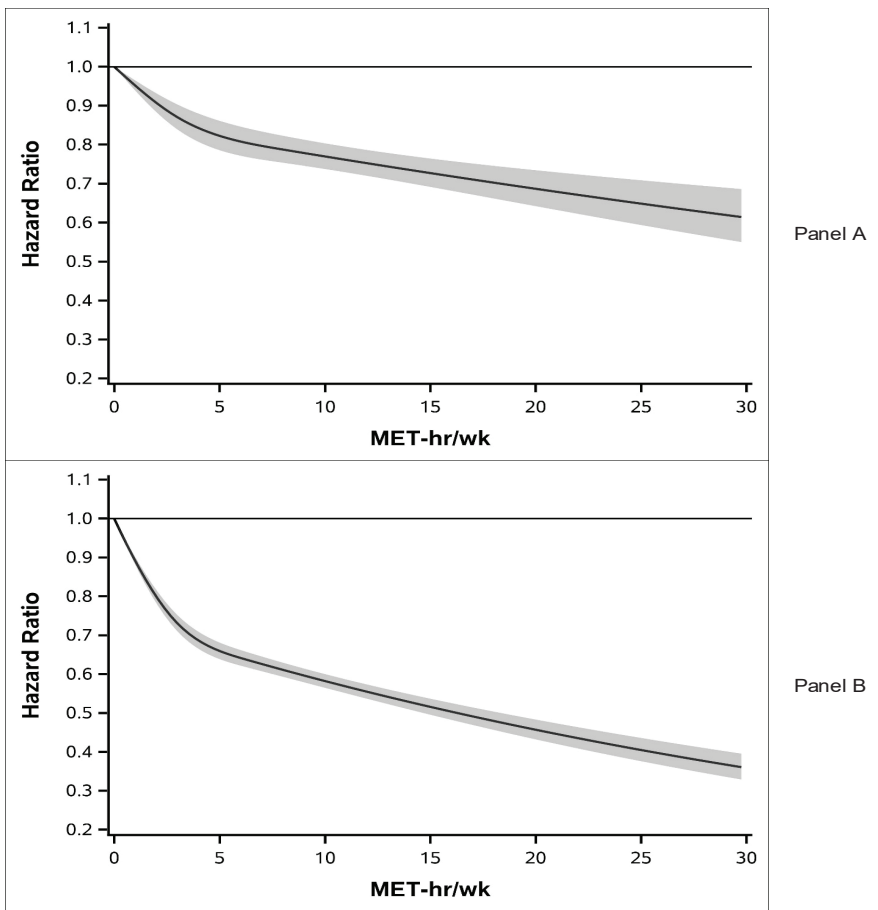

Figure 1: Restricted cubic spline depicting the relation of leisure time PA with risk of CVD (Panel A) and mortality (Panel B).Adjusted for age, sex, race, education, body mass index, smoking, alcohol intake, and DASH score. 3 knots at 25 th, 50 th and $75 \%$ percentile and using 0 MET-h/week as reference. All p non-linear trend $<0.0001$.

Table 3: Hazard ratios $(95 \% \mathrm{Cl})$ for total mortality by leisure time physical activity in the Million Veteran Program $(\mathrm{N}=438,364)$.

\begin{tabular}{|c|c|c|c|c|}
\hline $\begin{array}{c}\text { Quintiles of leisure } \\
\text { time activity } \\
\text { (MET-h/week) }\end{array}$ & Cases/N & $\begin{array}{c}\text { Crude } \\
\text { incidence } \\
(/ 1000 P Y)\end{array}$ & Crude & \multicolumn{2}{|c|}{ SIPTW } \\
\hline Q1 (0) & $16,696 / 91,888$ & 55.6 & $1.00($ ref $)$ & $1.00($ ref $)$ \\
\hline Q2 (0.1-1.24) & $10,677 / 91,234$ & 35.3 & $0.65(0.63,0.67)$ & $0.73(0.71,0.76)$ \\
\hline Q3 (1.25-3.80) & $7,585 / 79,405$ & 28.6 & $0.52(0.51,0.54)$ & $0.61(0.59,0.64)$ \\
\hline Q4 (3.81-6.60) & $7,962 / 88,858$ & 26.8 & $0.49(0.47,0.50)$ & $0.59(0.57,0.62)$ \\
\hline Q5 (6.61-30) & $5,405 / 86,979$ & 18.6 & $0.34(0.33,0.35)$ & $0.48(0.46,0.5)$ \\
\hline p linear trend & & & $<0.0001$ & $<0.0001$ \\
\hline
\end{tabular}

${ }^{\dagger}$ Adjusted for age, sex, race, education, body mass index, smoking, alcohol intake, DASH score and CVD at baseline.

mortality were stronger in the highest tertile of television watching and computer work (all p interaction $<0.05$, Figure 2). Time spent on video games did not modify PA-CVD or PAmortality relation (all $\mathrm{p}$ for interaction $>0.05$ ), data not shown. In sensitivity analyses excluding subjects with follow up time below 1 year did not alter the main results ( $\mathrm{p}$ linear trend $<0.0001)$.

\section{Discussion}

\section{Main findings}

In this large and well-characterized cohort of US veterans, we observed an inverse association of leisure time PA with incidence of CVD (CAD and ischemic stroke) as well as mortality (including CVD and cancer mortality) after adjustment for potential confounding factors. No meaningful association 

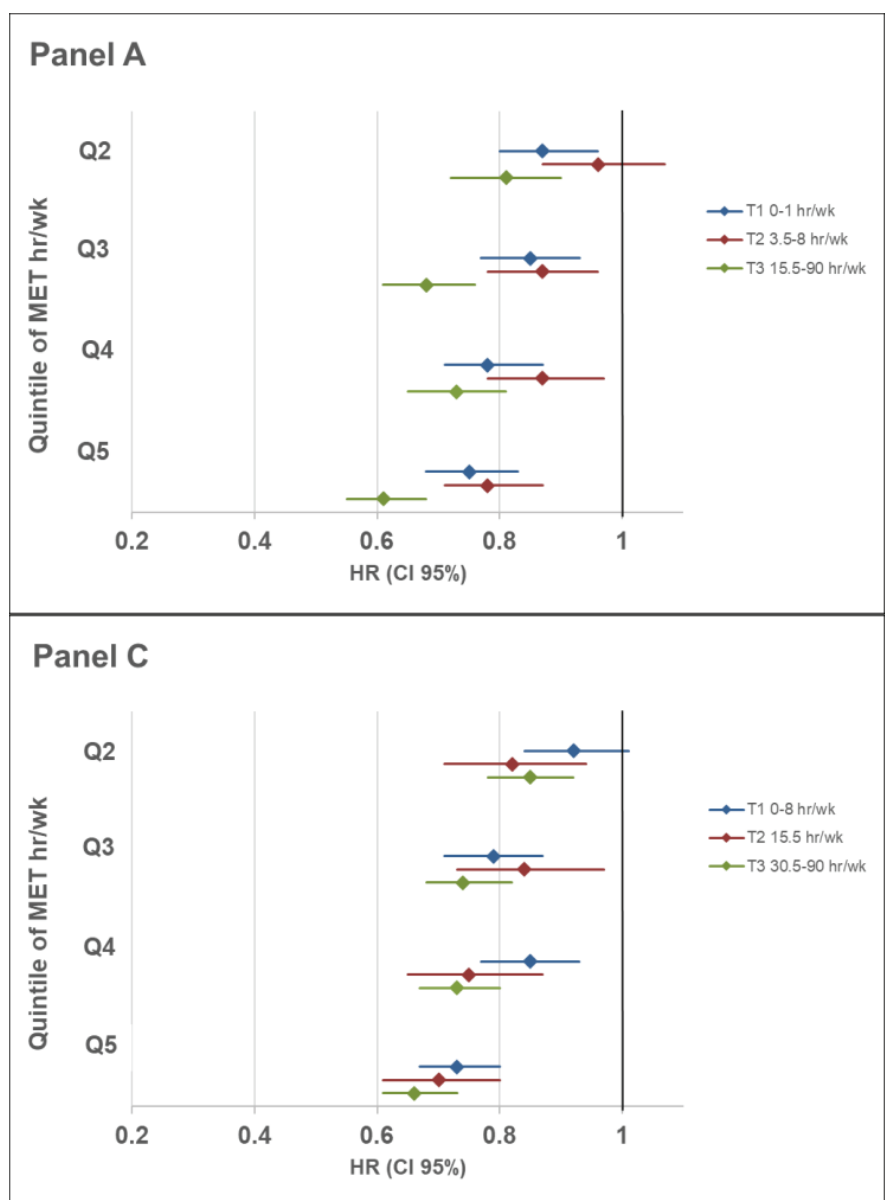

Panel B

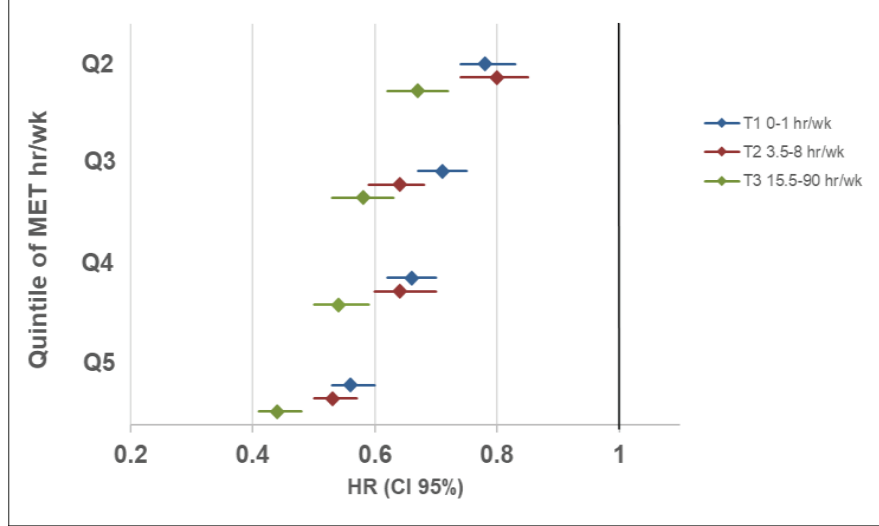

Panel D

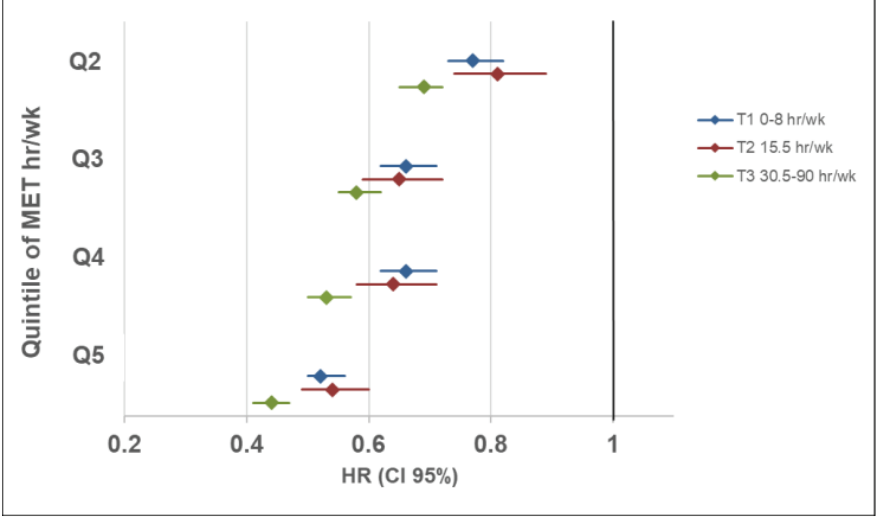

Figure 2: Forest plots of hazard ratio $(95 \% \mathrm{Cl})$ of PA with incident CVD and mortality stratified by (i) computer time (panels A and B) and (ii) TV watching (panels C and D), respectively.

of leisure time PA and incidence of hemorrhagic stroke was observed in this cohort. Furthermore, the relations of leisure time PA with CVD and mortality were stronger in participants who spend more time watching television and working on computer. We did not find evidence of interaction between leisure time PA and time spent playing video games and risk of CVD or mortality.

\section{Leisure time PA and risk of CVD and mortality}

While physical inactivity has been ranked fourth among the leading risk factors for mortality worldwide [25], current evidence lends support to beneficial effects of leisure time PA on cardiometabolic risk [1]. In a meta-analyses of prospective cohorts [26], high level of leisure time PA was associated with a $39 \%$ lower risk of CVD ( $95 \%$ CI: $25 \%$ to $48 \%$ ) compared to low level of leisure time PA; corresponding reduction for moderate level of leisure time PA was $23 \%$ (95\% CI:10\% to $33 \%)$. Furthermore, there was an inverse and graded relation between leisure time PA with incidence of coronary artery disease and stroke in the same meta-analysis [26]. These results are consistent with the reported findings from MVP.

Our findings of inverse relation of leisure time PA with total and CVD mortality are also consistent with a meta-analysis of 44 prospective cohorts reporting a linear and inverse association of leisure-time PA with risk of cardiovascular mortality irrespective of age, sex, and prevalent CVD [27]. Our findings extend our current knowledge from existing data by also reporting inverse relation between leisure time PA with cancer mortality.

\section{Interaction of sedentary behavior with leisure time PA on risk of $\mathrm{CVD} /$ mortality}

Limited studies have examined the interaction of sedentary behavior with leisure time PA on the incidence of CVD and/or mortality. In the 45 and Up Study, sitting time was positively associated with total and CVD mortality in participants that did not exercise or those that did not meet recommendations for PA (at least 150 minutes of moderate to vigorous PA per week) after a median follow up of 8.9 years ( $\mathrm{p}$ interaction sitting time $\mathrm{x} P \mathrm{P}<0.001$ ) [28]. In contrast, sitting time was not associated with incidence of total or CVD death in participants who met PA guidelines [28]. In the Danish Health Examination Survey (2007-2008), the positive association of sitting time with all-cause mortality was stronger in people that were physically inactive than those who exercised regularly ( $p$ interaction <0.05) after 5.4 years of mean follow up; however, no interaction of PA with sitting time was observed for CHD [29]. In contrast, data from the prospective Women's Health Initiative Observational Study [30] showed a positive and linear 
relation of sitting time with incidence of CVD, irrespective of PA after a median follow up of $\mathbf{1 2 . 2}$ years ( $\mathrm{p}$ for interaction between sitting time and PA 0.94)

\section{Biologic mechanisms}

PA reduces the risk of CVD and mortality through its beneficial effects on cardiometabolic risk factors. Several randomized controlled trials have reported that an intervention with PA led to increased HDL-cholesterol, improvement of insulin sensitivity and resistance, and reduction in blood pressure and measures of adiposity [31-33]. Other randomized clinical trials have demonstrated beneficial effects of PA on inflammatory cytokines [34, 35], blood pressure [36], lipids [37], beta cell function [38], and oral glucose tolerance [39].

\section{Limitations and strengths of the study}

Our study has some limitations. First, we relied on selfreported PA and sedentary behaviors for current analyses and cannot exclude exposure misclassification in the data. Second, despite multivariable adjustment, unmeasured and/or residual confounding might still explain partially or completely observed association, given the observational design of our study. Third, it is possible that we missed some CVD events that occurred outside the VHA; however, those events would be minimal given the fact that medical records on care provided outside VA are sought after and captured in EHR. Fourth, we did not have information on duration of each bout of PA for accurate assessment. Fifth, MVP participants may not represent the entire US veteran population nor the overall US population for generalization of our findings. Nonetheless, this study has several strengths including a large sample size and adequate number of events to allow subgroup analyses; availability of data on major confounding factors for multivariable adjustment; complete ascertainment of mortality in the VHA, and the availability of adequate data on hemorrhagic stroke for subtype analyses.

\section{Conclusion}

Our data showed an inverse association of leisure time PA with risk of CVD and mortality with stronger effect size in participants with a higher propensity of adhering to sedentary behaviors among US veterans. These findings underscore the importance of following PA recommendations as a costeffective strategy to reduce the burden of CVD. Future studies are needed to explore biologic mechanisms underlying observed interaction of PA with sedentary behaviors in the general population.

\section{Declarations}

Ethics approval and consent to participate: Each participants signed informed consent and the study was approved by the Central VA Institutional Review Board, Washington DC.

\section{Availability of data and materials}

The datasets generated and/or analyzed during the current study are not publicly available in order to comply with the Department of Veterans Affairs Office of Research and Development policies designed to protect US Veterans' information.

\section{Funding}

This research is based on data from the Million Veteran Program, Office of Research and Development, Veterans Health Administration, MVPooo and MVPoo1 (VA Merit Awards BX004831 (Wilson/Cho), CXo01025 (Wilson/Cho)).

\section{Authors' contribution}

Luc Djousse: Designed the study, curated physical activity variable, directed statistical analyses, and drafted the manuscript.

Petra Schubert: Assisted with data curation and completed statistical analyses

Yuk-Lam Ho: Assisted with data curation, data analysis, quality control check of the SAS code

Stacey B. Whitbourne: Collected data and participated in data curation and analysis.

Kelly Cho: Contributed to data collection, supervision of analytical team, and curation of phenotypes

J. Michael Gaziano: Serves as one of the Principal Investigators of MVP, designed MVP study, secured funding, and supervised the team.

All co-authors contributed to data interpretation and approved the final version of the manuscript.

\section{Acknowledgement}

This publication does not represent the views of the Department of Veterans Affairs or the U.S. Government.

(Supplemental Tables and Figures)

\section{References}

1. Virani SS, Alonso A, Aparicio HJ, Benjamin EJ, Bittencourt MS, et al. (2021) Heart Disease and Stroke Statistics-2021 Update: A Report From the American Heart Association. Circulation 143: e254-e743. Link: https://bit.ly/39Pn1Qz

2. Djousse L, Driver JA, Gaziano JM (2009) Relation between modifiable lifestyle factors and lifetime risk of heart failure. JAMA 302: 394-400. Link: https://bit.ly/3kRC42q

3. Djousse L, Ho YL, Nguyen XT, Gagnon DR, Wilson PWF, et al. (2018) DASH Score and Subsequent Risk of Coronary Artery Disease: The Findings From Million Veteran Program. J Am Heart Assoc 7: e008089. Link: https://bit.ly/3ikSyP0

4. Patel YR, Gadiraju TV, Gaziano JM, Djousse L (2018) Adherence to healthy lifestyle factors and risk of death in men with diabetes mellitus: The Physicians' Health Study. Clin Nutr 37: 139-143. Link: https://bit.ly/3kUauSn

5. Barengo NC, Antikainen R, Borodulin K, Harald K, Jousilahti P (2017) LeisureTime Physical Activity Reduces Total and Cardiovascular Mortality and Cardiovascular Disease Incidence in Older Adults. J Am Geriatr Soc 65: 504510. Link: https://bit.ly/3F6Z6dK

6. Quan $M$, Xun $P$, Wang $R$, He K, Chen $P$ (2020) Walking pace and the risk of stroke: A meta-analysis of prospective cohort studies. J Sport Health Sci 9: 521-529. Link: https://bit.ly/3ofA4TU

7. US Department of Health and Human Services (2018) Physical Activity 
Guidelines for Americans. $2^{\text {nd }}$ ed. Department of Health and Human Services Link: https://bit.ly/3AVcFKJ

8. Arnett DK, Blumenthal RS, Albert MA, Buroker AB, Goldberger ZD, et al. (2019) ACC/AHA Guideline on the Primary Prevention of Cardiovascular Disease: A Report of the American College of Cardiology/American Heart Association Task Force on Clinical Practice Guidelines. Circulation 140: e596-e646. Link: https://bit.ly/3uqkaa6

9. Patterson $\mathrm{R}$, McNamara E, Tainio $M$, de Sa TH, Smith AD, et al. (2018) Sedentary behaviour and risk of all-cause, cardiovascular and cancer mortality, and incident type 2 diabetes: a systematic review and dose response metaanalysis. Eur J Epidemiol 33: 811-829. Link: https://bit.ly/2XXG7Bo

10. Dickins KA, Buchholz SW, Rivero T, Miller C (2018) A review of reviews: Sedentary behaviour and cardiovascular disease specific to older people. Int J Older People Nurs 13: e12211. Link: https://bit.ly/3unNdey

11. Ekelund U, Tarp J, Steene-Johannessen J, Hansen BH, Jefferis B, et al. (2019) Dose-response associations between accelerometry measured physical activity and sedentary time and all cause mortality: systematic review and harmonised meta-analysis. BMJ 366: 14570. Link: https://bit.ly/3uDgimB

12. Gaziano JM, Concato J, Brophy M, Fiore L, Pyarajan S, et al. (2016) Million Veteran Program: A mega-biobank to study genetic influences on health and disease. J Clin Epidemiol 70: 214-223. Link: https://bit.ly/3AXA9yX

13. Ainsworth BE, Haskell WL, Leon AS, Jacobs DR, Jr., Montoye HJ, et al. (1993) Compendium of physical activities: classification of energy costs of human physical activities. Med Sci Sports Exerc 25: 71-80. Link: https://bit.ly/3kWiXUQ

14. Center of Excellence for Suicide Prevention. Joint Department of Veterans Affairs (VA) and Department of Defense (DoD) Suicide Data Repository National Death Index (NDI).

15. Floyd JS, Blondon M, Moore KP, Boyko EJ, Smith NL (2016) Validation of methods for assessing cardiovascular disease using electronic health data in a cohort of Veterans with diabetes. Pharmacoepidemiol Drug Saf 25: 467-471. Link: https://bit.ly/3mgnelP

16. Liao KP, Sun J, Cai TA, Link N, Hong C, et al. (2019) High-throughput multimodal automated phenotyping (MAP) with application to PheWAS. J Am Med Inform Assoc 26: 1255-1262. Link: https://bit.ly/3kRDSse

17. Imran TF, Posner D, Honerlaw J, Vassy JL, Song RJ, et al. (2018) A phenotyping algorithm to identify acute ischemic stroke accurately from a national biobank: the Million Veteran Program. Clin Epidemiol 10: 1509-1521. Link: https://bit.ly/3urMQQ0

18. Rimm EB, Giovannucci EL, Stampfer MJ, Colditz GA, Litin LB, et al. (1992) Reproducibility and validity of an expanded self-administered semiquantitative food frequency questionnaire among male health professionals. Am J Epidemiol 135: 1114-1126. Link: https://bit.ly/3zZ8qN4

19. US Department of Veterans Affairs. System of Records Notice 97VA10P1: Consolidated Data Information System-VA. 76 FR 25409. May 4, 2011.

20. McCaffrey DF, Griffin BA, Almirall D, Slaughter ME, Ramchand R, et al (2013) A tutorial on propensity score estimation for multiple treatments using generalized boosted models. Stat Med 32: 3388-3414. Link: https://bit.ly/3CQnw9A

21. Greifer N (2020) Weightlt: Weighting for Covariate Balance in Observational Studies.

22. Greenwell BB, Cunningham J (2020) Generalized Boosted Regression Models Link: https://bit.ly/3uqlZ5N

23. Gagnon DR (2020) Producing Publication-Ready Spline Plots. Link:
https://bit.ly/3kUarFZ

24. Greifer N, Greifer N (2020) cobalt: Covariate Balance Tables and Plots.

25. Global 2010 Recommendations on Physical Activity for Health. WHO. Link: https://bit.ly/3ikVTOu

26. Li J, Loerbroks A, Angerer P (2013) Physical activity and risk of cardiovascular disease: what does the new epidemiological evidence show? Curr Opin Cardiol 28: 575-583. Link: https://bit.ly/3zX1cJk

27. Cheng W, Zhang Z, Cheng W, Yang C, Diao L, et al. (2018) Associations of leisure-time physical activity with cardiovascular mortality: A systematic review and meta-analysis of 44 prospective cohort studies. Eur J Prev Cardiol 25: 1864-1872. Link: https://bit.ly/3AQGmwF

28. Stamatakis E, Gale J, Bauman A, Ekelund U, Hamer M, et al. (2019) Sitting Time, Physical Activity, and Risk of Mortality in Adults. J Am Coll Cardiol 73 2062-2072. Link: https://bit.ly/3kRJIPM

29. Petersen CB, Thygesen LC, Helge JW, Gronbaek M, Tolstrup JS (2010) Time trends in physical activity in leisure time in the Danish population from 1987 to 2005. Scand J Public Health 38: 121-128. Link: https://bit.ly/3oiFnC3

30. Chomistek AK, Manson JE, Stefanick ML, Lu B, Sands-Lincoln M, et al (2013) Relationship of sedentary behavior and physical activity to inciden cardiovascular disease: results from the Women's Health Initiative. J Am Coll Cardiol 61: 2346-2354. Link: https://bit.ly/39Tr1iW

31. Goodpaster BH, Delany JP, Otto AD, Kuller L, Vockley J, et al. (2010) Effects of diet and physical activity interventions on weight loss and cardiometabolic risk factors in severely obese adults: a randomized trial. JAMA 304: 17951802. Link: https://bit.ly/3okUJ9d

32. Coen PM, Tanner CJ, Helbling NL, Dubis GS, Hames KC, et al. (2015) Clinical trial demonstrates exercise following bariatric surgery improves insulin sensitivity. J Clin Invest 125: 248-257. Link: https://bit.ly/3uy9bf6

33. Kemmler W, Kohl M, von Stengel S, Fröhlich M, Jakob F, et al. (2020) Effect of high-intensity resistance exercise on cardiometabolic health in older men with osteosarcopenia: the randomised controlled Franconian Osteopenia and Sarcopenia Trial (FrOST). BMJ Open Sport Exerc Med 6: e000846. Link: https://bit.ly/3zQnRad

34. Monteiro-Junior RS, de Tarso Maciel-Pinheiro $P$, da Matta Mello Portugal E, da Silva Figueiredo LF, Terra R, et al. (2018) Effect of Exercise on Inflammatory Profile of Older Persons: Systematic Review and Meta-Analyses. J Phys Act Health 15: 64-71. Link: https://bit.ly/2XVZJ8Z

35. Tartibian B, FitzGerald LZ, Azadpour N, Maleki BH (2015) A randomized controlled study examining the effect of exercise on inflammatory cytokine levels in post-menopausal women. Post Reprod Health 21: 9-15. Link: https://bit.ly/3mi9l6G

36. Modesto BT, Bartholomeu T, Basso L, Costa LAR, Tinucci T, et al. (2021) Effects of a Real-Life Park-Based Physical Activity Interventional Program on Cardiovascular Risk and Physical Fitness. Prev Chronic Dis 18: E18. Link: https://bit.ly/3ihrksl

37. Javaherian M, Dabbaghipour N, Mohammadpour Z, Attarbashi Moghadam B (2020) The role of the characteristics of exercise-based cardiac rehabilitation program in the improvement of lipid profile level: A systematic review and meta-analysis. ARYA Atheroscler 16: 192-207. Link: https://bit.ly/3ijQs22

38. Heiskanen MA, Motiani KK, Mari A, Saunavaara V, Eskelinen JJ, et al. (2018) Exercise training decreases pancreatic fat content and improves beta cell function regardless of baseline glucose tolerance: a randomised controlled trial. Diabetologia 61: 1817-1828. Link: https://bit.ly/3A1sSgw

Citation: Djousse L, Schubert P, Ho YL, Whitbourne SB, Cho K, et al. (2021) Leisure time physical activity, sedentary behavior and risk of cardiovascular disease and mortality among US Veterans. J Nov Physiother Phys Rehabil 8(2): 033-039. DOI: https://dx.doi.org/10.17352/2455-5487.000091 